\title{
Histological assessment of tangentially excised burn eschars
}

\author{
Reuven Gurfinkel $M D^{1}$, Lior Rosenberg $M D^{1}$, Sarit Cohen $M D^{1}$, \\ Arnon Cohen $\mathrm{MD}^{1}$, Alex Barezovsky MD ${ }^{1}$, Emanuela Cagnano $\mathrm{MD}^{2}$, Adam J Singer $\mathrm{MD}^{3}$
}

R Gurfinkel, L Rosenberg, S Cohen, et al. Histological assessment of tangentially excised burn eschars. Can J Plast Surg 2010;18(3):e33-e36.

BACKGROUND: The burn eschar serves as a medium for bacterial growth and a source of local and systemic infection. To prevent or minimize these complications, it is important to debride the eschar as early as possible.

OBJECTIVE: To identify the presence of viable skin within the excisions by examining tangentially excised burn eschars.

METHODS: A total of 146 samples of burned human tissue were removed during 54 routine sharp tangential excision procedures (using dermatomes). The samples were histologically examined to identify the relative thickness of the dead, intermediate and viable layers.

RESULTS: The mean $( \pm$ SD) thickness of the excised samples was $1.7 \pm 1.1 \mathrm{~mm}$. The sacrificed viable tissue (mean thickness $0.7 \pm 0.8 \mathrm{~mm}$ ) occupied $41.2 \%$ of the entire thickness of the excision. In 32 biopsies ( $21.8 \%$; $95 \%$ CI 16.0 to 29.3 ), the excision did not reach viable skin. Only eight biopsies $(5.4 \%$; 95\% CI 2.8 to 10.1$)$ contained all of the necrotic tissue without removing viable tissue.

CONCLUSIONS: The thickness of a single tangentially excised layer of eschar is not much greater than the actual thickness of the entire skin and often contains viable tissue. Because surgical debridement is insufficiently selective, more selective means of debriding burn eschars should be explored.

Key Words: Burns; Dermatome; Eschar; Tangential excision

$\mathrm{B}$ urn injuries result in the formation of dead tissue known as an eschar. Similar to burns, the depth of the eschar may be superficial or deep. The presence of the nonviable eschar serves as a nidus for bacterial growth and may result in an inflammatory response, both of which may contribute to the extension of the burn injury as well as local and systemic infection (1). As a result, removal of the dead eschar is considered to be a cornerstone of burn wound therapy, and most burn centres have adopted early surgical debridement (tangential or, in lifethreatening burns, fascial excision avulsion) of the burn wound $(2-5)$. This approach, however, is not without hazard. While generally producing better functional and cosmetic results than expectant conservative management, a high price is paid in terms of surgical and anesthetic trauma, bleeding, the sacrifice of remaining viable healthy tissue and the need for larger donor site areas (1-16).

Initial diagnosis of the eschar's extent is the first step in any debridement strategy. However, the assessment of burn depth through the opaque eschar is difficult, if not impossible, even with advanced diagnostic methods such as photographic infrared, ultrasound and laser Doppler imaging (16-30). Furthermore,

\section{L'évaluation histologique des escarres de brûlures séparées par excision tangentielle}

\begin{abstract}
HISTORIQUE : L'escarre de brûlure est un médium de croissance bactérienne et une source d'infection locale et systémique. Pour prévenir ou réduire au minimum ces complications, il est important de débrider l'escarre le plus rapidement possible.

OBJECTIF : Déterminer la présence de peau viable dans les excisions par l'examen des escarres de brûlures séparées par excision tangentielle.

MÉTHODOLOGIE : Au total, on a procédé à la séparation de 146 échantillons de tissus humains brûlés dans le cadre de 54 interventions systématiques d'excision tangentielle tranchante (au moyen de dermatomes). Les échantillons ont fait l'objet d'un examen histologique afin de déterminer l'épaisseur relative des couches morte, intermédiaire et viable.

RÉSULTATS : L'épaisseur moyenne ( \pm ÉT) des échantillons excisés était de $1,7 \pm 1,1 \mathrm{~mm}$. Le tissu viable sacrifié (épaisseur moyenne de $0,7 \pm 0,8 \mathrm{~mm}$ ) occupait 41,2 \% de toute l'épaisseur de l'excision. Dans 32 biopsies (21,8\%; $95 \%$ IC 16,0 à 29,3), l'excision n'atteignait pas la peau viable. Seulement huit biopsies (5,4 \%; 95 \% IC 2,8 à 10,1) contenaient la totalité des tissus nécrotiques, sans tissus viables.

CONCLUSIONS : L'épaisseur d'une seule couche d'escarre séparée par excision tangentielle n'est pas tellement plus importante que toute l'épaisseur de la peau et contient souvent des tissus viables. Puisque le débridement chirurgical n'est pas assez sélectif, il faudrait explorer des modes plus sélectifs de débridement des escarres de brûlure.
\end{abstract}

the burn's depth is not constant within the damaged area, and the eschar's color and texture may be misleading even to experts. Very often, the extent and depth of tissue damage may only be determined after a few days, when the secondary damage already extends beyond the original denatured and destroyed tissues.

The most obvious and direct method of debridement is surgical excision. To minimize damage to the underlying and surrounding viable tissue, sequential excision of thin layers of burned skin termed 'tangential excision' is often performed. Generally, the adequacy of the excision is determined by the presence of small punctate bleeding points within the dermis that suggest the viability of the underlying skin. Thus, the assessment of the thoroughness of the excision is visual, based on the appearance of bleeding points and the appearance of the excised tissue - both of which have never been validated.

Due to the crude nature of tangential excision, the end result is often a full thickness defect with minimal, if any, epithelial remnants limiting the possibility of spontaneous healing. As a result, the raw exposed fat or deep dermis needs to be covered with a skin graft or skin substitute to prevent desiccation

${ }^{1}$ Department of Plastic $\mathcal{E}$ Reconstructive Surgery, The Burn Unit; ${ }^{2}$ Institute of Pathology, Soroka University Medical Center, The Center for REDD, Ben-Gurion University of the Negev, Beer-Sheva, Israel; ${ }^{3}$ Department of Emergency Medicine, Stony Brook University, Stony Brook, New York, USA

Correspondence: Dr Reuven Gurfinkel, Department of Plastic $\mathcal{E}$ Reconstructive Surgery, The Burn Unit, Soroka University Medical Center and Faculty of Health Sciences, Ben-Gurion University of the Negev, PO Box 151, Beer-Sheva, 84101 Israel. Telephone 972-8-640-0880,

fax 972-8-640-3033, e-mail jaba1234@gmail.com 
TABLE 1

Thickness of excised tissue

\begin{tabular}{lccccc}
\hline & $\begin{array}{c}\text { Tangential } \\
\text { excisions, thickness, } \\
\mathbf{n}\end{array}$ & $\begin{array}{c}\text { mm } \\
\mathbf{m m}\end{array}$ & $\begin{array}{c}\text { Maximum } \\
\text { thickness, } \\
\mathbf{m m}\end{array}$ & $\begin{array}{c}\text { Mean } \pm \mathbf{~ S D , ~} \\
\mathbf{m m}\end{array}$ & Total, \% \\
\hline Necrotic & 146 & 0 & 2.7 & $0.9 \pm 0.6$ & 52.9 \\
Intermediate & 146 & 0 & 1.2 & $0.1 \pm 0.2$ & 5.9 \\
Viable & 146 & 0 & 7.0 & $0.7 \pm 0.8$ & 41.2 \\
Total & 146 & 0 & 9.1 & $1.7 \pm 1.1$ & 100.0 \\
\hline
\end{tabular}

and further necrosis and scarring. Thus, surgical debridement is often tied to the availability of an adequate, immediate cover. In many cases, the insult of the surgical debridement (and of the autograft harvesting that usually follows) is considerable, necessitating careful judgment of the procedure's extent.

At the Soroka University Medical Center (Beer-Sheva, Israel), sharp tangential excision (STE) using a dermatome is the standard of care, with dermabrasion reserved for smaller areas and more superficial burns; avulsion debridement is used for the deeper and more extensive burns. To assess the thoroughness and extent of our STE, we measured the thickness of the excised eschar and examined the excised tissue for the presence of healthy viable tissue.

\section{METHODS}

\section{Study design}

A prospective, blinded, descriptive study design was used to determine the depth of the eschar and selectivity of STE in burn patients. The study was approved by the Institutional Review Board, and all patients gave written informed consent.

\section{Setting}

The study was conducted in an urban, tertiary care, academic medical centre with a regional burn centre.

\section{Interventions}

For many years, the standard of care for burn excision at the Department of Plastic \& Reconstructive Surgery, The Burn Unit at the Soroka University Medical Center has been the classical layer-by-layer STE using Watson or Rosenberg manual dermatomes, until a punctated bleeding wound bed was revealed. In the present study, samples of burned tissues removed during routine STE were histologically examined for the relative thicknesses of the necrotic, intermediate and viable layers. The samples were excised by six different burn surgeons during 54 consecutive routine burn STE procedures. The surgeons were asked to select the samples that they believed reached the viable tissues. No other instructions concerning the eschar, debridement technique or a specific body area were given. The surgeons were unaware of the study objectives.

\section{Tissue processing}

Each tangentially excised tissue sample was placed into a biopsy vial containing $10 \%$ formaldehyde, and sent for histopathology examination. The hospital dermatopathologist took three biopsies from the sample's longest axis: $1 \mathrm{~cm}$ from each edge and from the centre. After fixation and hematoxylin and eosin staining, the samples were examined by a board-certified pathologist. The depth of injury was measured, and the thickness of the burn

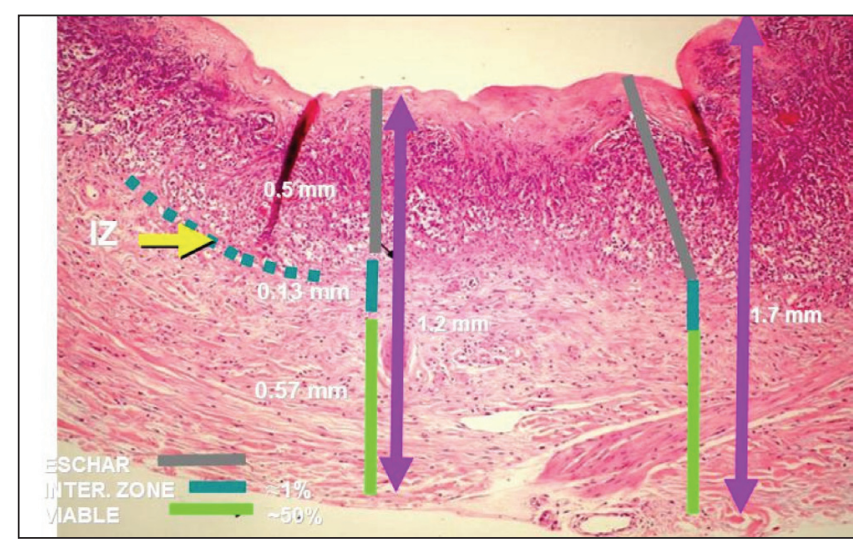

Figure 1) Representative micrograph of excised eschar. The upper dermis is necrotic, while the lower portion is viable. The yellow arrow indicates the intermediate layer between the necrotic and viable layers. IZ Interzone

eschar, healthy tissue and the interposing, intermediate layer were determined. The intermediate layer was defined as the tissue immediately below the dead eschar and above the obviously unharmed tissue. This area typically included changes such as hyperemia, stasis and neutrophil infiltration, probably corresponding to the zone of stasis/ischemia $(31,32)$. The surgical team was not involved in the examination of the tissue samples and the pathologist was not involved in the surgical phase.

\section{Data analysis}

Continuous data are presented as mean $\pm \mathrm{SD}$. Binomial data are presented as the per cent frequency of occurrence and 95\% CI. Only descriptive statistics were used in the observational study.

\section{RESULTS}

A total of 146 tangential excisions of burns were obtained from 54 patients. Burn etiology included flame burns (63\%), scalds (33\%) and chemical burns (4\%). The mean total body surface area was $20.8 \%$ (range $2 \%$ to $55 \%$ ). The burns were located on the lower extremities (54\%), upper extremities (25\%), trunk $(15 \%)$, and head and neck (6\%).

The mean $( \pm$ SD) thickness of the excised samples was $1.7 \pm 1.1 \mathrm{~mm}$ (Table 1$)$. The mean thickness of the necrotic tissue was $0.9 \pm 0.6 \mathrm{~mm}$, while that of the intermediate zone was $0.1 \pm 0.2 \mathrm{~mm}$. The mean thickness of the viable excised tissue was $0.7 \pm 0.8 \mathrm{~mm}$ (Table 1, Figure 1), which represented $41.2 \%$ of the entire thickness of the excision. In 32 of the biopsies (21.8\%; 95\% CI 16.0 to 29.3), the excision did not reach the intermediate layer or healthy tissue (Figure 2). Only eight biopsies (5.4\%; 95\% CI 2.8 to 10.1]) contained all of the necrotic tissue without removing viable tissue.

\section{DISCUSSION}

Burn debridement is an important and complex process that is often critical to the future of the wound and the patient's wellbeing. Multiple methods are presently used to debride burn eschars. The most rapid and commonly used method is surgical excision. Traditional surgical excision removes large 'chunks' of tissue and is the least selective method of debridement. Surgical tangential excision is more selective because it is performed in stages, layer by layer until the appearance of normal 
healthy tissue. As a result, STE is the standard method of eschar debridement in many burn centres such as ours.

The results of our study demonstrate that surgical tangential excision of burn eschars often results in the removal of the entire thickness of the dermis. Furthermore, nearly one-half of the excised tissue is viable and healthy in appearance, demonstrating the poor selectivity of surgical tangential excision. Because the ability of the remaining skin to heal spontaneously is dependent on the presence of an underlying dermis and epithelial adnexa, our results question the wisdom of routine surgical tangential excision in burn eschar management.

The depth of tangential excision depends on several factors. The first determinant of depth of excision is the setting of the dermatome. However, the pressure on the skin, the dermatome angle, the body area, and the local tissue's tone and resilience are also important and are difficult to determine in the clinical setting. The thickness of the excision was measured regardless of the patient's age and body area (both influencing the skin thickness). We did not record the number of skin grafts that were taken because the number of obtainable skin grafts depend on many other factors - the thoroughness of the debridement being one of them (32).

In most body areas, the thickness of the skin ranges from $0.5 \mathrm{~mm}$ to $3 \mathrm{~mm}(33,34)$. In some areas (eg, the eyelids), the skin may be thinner than $1 \mathrm{~mm}$ and, in others (eg, the shoulders, parts of the plantar skin), it may be thicker. In young children and the elderly, the skin is thinner. Various pathological and medical conditions and treatments may also influence the thickness of the skin. For the skin to heal with minimal scarring, a dermal matrix and epithelial elements are required. The layer of skin that is richest in epithelial tissue is the more superficial papillary dermis with the invaginating epithelial adnexa and the rete pegs with their basal membrane. This layer is approximately $0.5 \mathrm{~mm}$ or thinner. Below the papillary dermis, the only epithelial elements are the skin appendages (hair follicles, sweat and sebaceous glands). The thicker the dermal matrix, the more likely that spontaneous epithelialization will occur. The fastest healing (epithelialization) occurs with superficial defects limited to the papillary dermis level (the level of a very thin split-thickness skin graft donor site). The deeper the cutaneous defect, the slower and less complete is the healing process due to a thin dermal matrix and sparse epithelial elements. With deep cutaneous defects that extend below the level of the dermis, healing occurs by formation of granulation tissue and scarring (healing by secondary intention).

Despite its widespread use, few studies (31,32,35-37) have addressed the adequacy of surgical tangential excision. One study (31) examined excised burn eschars from 15 patients, nine of whom were children. In the group of nine children, only $50 \%$ of the excised eschar was necrotic. In the group of six adults, $90 \%$ of the eschar was necrotic. In contrast to our study, the tissue samples were microscopically examined by the same surgeons who excised the eschar, introducing significant observer bias.

STE of a very thin burn eschar layer is technically very difficult and a second passage of the excising dermatome on an already excised bed yields inconsistent layers. Thus, for an effective STE, the dermatome is usually set at an excision thickness of $0.5 \mathrm{~mm}$ to $2 \mathrm{~mm}$; the excision is performed layer by layer parallel to the skin surface regardless of the variations

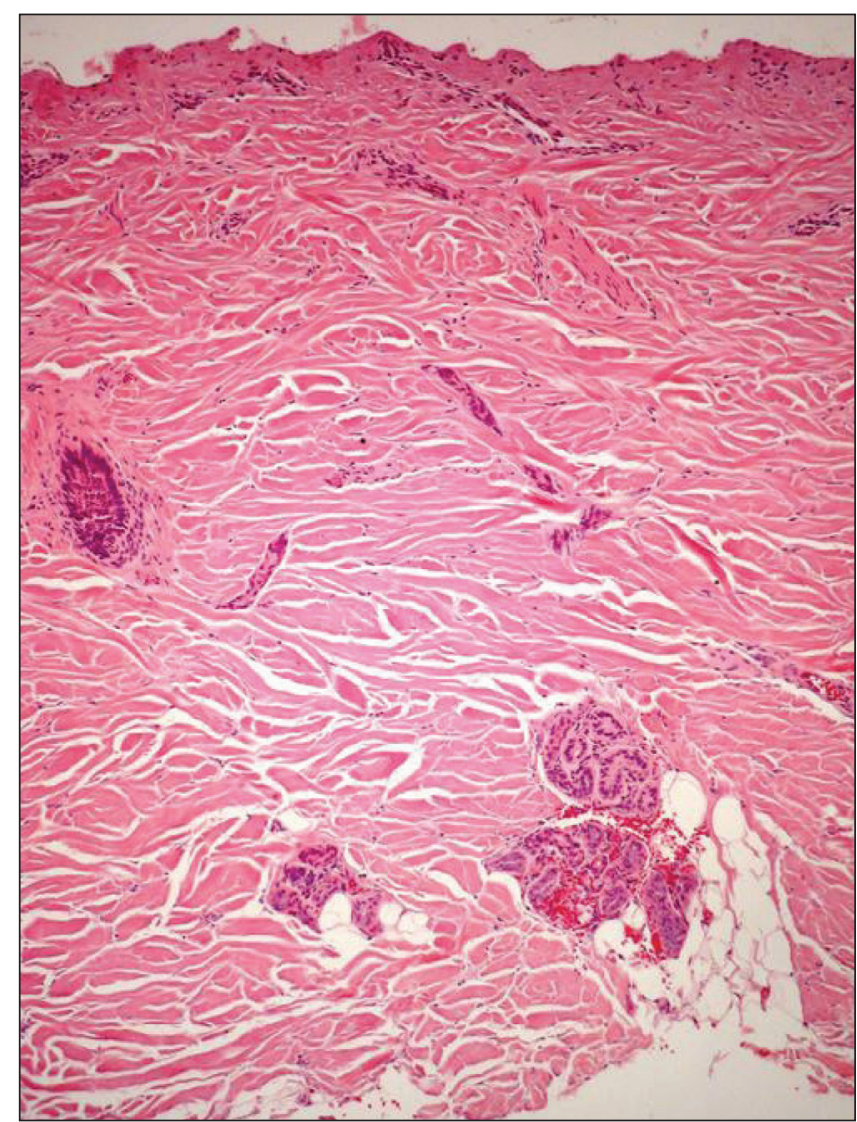

Figure 2) Micrograph of excised eschar. The entire thickness of the tissue is necrotic suggesting that the eschar was not sufficiently debrided

in the eschar's depth from point to point. In areas of thicker skin, thicker eschar or possibly a more aggressive surgeon, the setting of the dermatome may be even deeper. Thus, in most body areas, the first STE will remove a layer including the entire papillary dermis and sometimes even most of the reticular dermis. The second or subsequent excisions in most cases will leave large areas of exposed subdermal fat without any spontaneous healing potential. This is the reason why in most cases, STE necessitates the use of a split-thickness skin graft. To preserve the healing potential, a more selective surgical tangential debridement (eg, dermabrasion) may be attempted, although it is time consuming and skill dependent.

A number of nonsurgical eschar debridement methods have also been described. Chemical debridement, using chemical compounds such as enzymes, is generally a slow process. With the exposure method, the eschar is left to desiccate and maceration of the entire eschar (secondary to autolysis) eventually occurs. Unfortunately, these methods often require multiple dressing changes, can be painful and can expose the patient to the risk of infection and sepsis over extended periods of time. Thus, an ideal method of eschar debridement that is effective, rapid and selective is needed.

\section{Limitations}

Our study has several limitations that merit further discussion. First, we cannot exclude a Hawthorne effect because the surgeons were aware that we were collecting the excised tissue, although the exact nature of the study was mostly unknown. 
Thus, it is possible that some were more careful than usual when performing a tangential excision. This may have led to an underestimation of the depth of excision and extent of injury to surviving viable tissue. This may explain the large number of incomplete excisions (roughly one in five), and the fact that complete debridement without sacrificing healthy tissue was achieved in so few cases. Second, our study is limited to a single burn centre and a few surgeons. However, our centre and surgeons perform many such operations each year. Thus, it is unclear whether our results can be generalized to most or other centres.

\section{CONCLUSIONS}

Based on our preliminary data, the thickness of eschar debrided by STE is not much different than the actual thickness of the entire skin. Nearly one-half of the excised tissue was healthy or viable, while nearly one-quarter of the excised samples did not remove the entire eschar. On the basis of these data, and in accordance with the widely held clinical impression, it seems that we pay a high price for STE debridement of the burn eschar. These results suggest that STE, at least in our hands, more often than not removes viable tissue. The consequence in many cases is likely to be a reduced potential for spontaneous healing in more superficial dermal burns and conversion into full-thickness defects in deeper dermal burns.

Similar studies should be conducted in other centres and by more surgeons to determine the external validity of our results. If similar results are found, there is a need to develop more refined surgical techniques or other rapid nonsurgical means should be explored to debride burn eschars.

Presented in part at the Annual Meeting of the American Burn Association, May 2008, Chicago, Illinois, USA.

\section{REFERENCES}

1. Singh V, Devgan L, Bhat S, Milner SM. The pathogenesis of burn wound conversion. Ann Plast Surg 2007;59:109-15.

2. Janzekovic Z. A new concept in the early excision and immediate grafting of burns. J Trauma 1970;10:1103-8.

3. Jackson DM, Stone PA. Tangential excision and grafting of burns. Br J Plast Surg 1972;25:416.

4. Lavrance JC, Carney SA. Tangential excision of burns; studies on the metabolic activity of the recipient areas for skin grafts. Br J Plast Surg 1973;26:93.

5. Monafo WW. Tangential excision. Clin Plast Surg 1974;1:591-601.

6. Solomon J. Early surgical excision and grafting of burns including tangential excision. Prog Pediatr Surg 1981;14:133-49.

7. Baxter CR. Management of burn wounds. Dermatol Clin 1993;11:709-14.

8. Prasanna M, Singh K, Kumar P. Early tangential excision and skin grafting as a routine method of burn wound management: An experience from a developing country. Burns 1994;20:446-50.

9. Sheridan RL, Tompkins RG, Burke JF. Management of burn wounds with prompt excision and immediate closure. J Intensive Care Med 1994;9:6-17.

10. Laterjet J. A simple guide to burn treatment. Burns 1995;21:221.

11. Papini RP, Wilson AP, Steer JA, McGrouther DA, Parkhouse N. Wound management in burn centres in the United Kingdom. Br J Surg 1995;82:505-9.

12. Heimbach D, Mann R, Engrav L. Evaluation of the burn wound. 16 management decisions. Total Burn Care. Herndon: WB Saunders, 1997:81-7.

13. Kisslaogglu E Yuksel F, Uccar C, Karacaogglu E. Rationale for early tangential excision and grafting in burn patients. Acta Chir Plast 1997;39:9-12.

14. Sheridan R, Remensnyder J, Prelack K, Petras L, Lydon M. Treatment of the seriously burned infant. J Burn Care Rehabil 1998;19:115-8.

15. Subrahmanyam M. Early tangential excision and skin grafting of moderate burns is superior to honey dressing: A prospective randomised trial. Burns 1999;25:729-31.

16. Tredget E. Management of the acutely burned upper extremity. Hand Clin 2000;16:187-203.

17. Jackson DM. Historical review of the use of local physical signs in burns. Br J Plast Surg 1970;23:211.

18. Kalus AM. Application of ultrasound in assessing burn depth. Lancet 1979;28:188.

19. Watchel TL, Leopald GR, Frank HA, Frank DH. B-mode 21 ultrasonic echo determination of depth of thermal injury. Burns 1986;12:432.

20. Rosenberg L, Molcho J, Dotan Y, Baruchin A, Mahler D. Use of the Doppler effect in visible laser light to assess tissue viability by capillary blood flow. Ann Plast Surg 1982;8:206-12.

21. Albsjom B, Micheels J, Sorensen B. Laser Doppler flowmetry measurements of superficial dermal, deep dermal and subdermal burns. Scand J Plast Reconstr Surg 1984;18:75.

22. Essex TJH, Byrne PO. A laser Doppler scanner for imaging blood flow in skin. J Biomed Eng 1991;13:189-94.

23. Koruda MJ, Zimbler A, Settle RG. Assessing burn wound depth using in vitro nuclear magnetic resonance (NMR). J Surg Res 1986;40:475.

24. Kaufman T, Hurwitz D, Heggers J. The India ink injection technique to assess the depth of experimental burn wounds. Burns 1984;10:405.

25. Davies M, Adendorff D, Rode H, van de Reit IS. Coloring the damaged tissues on the burn wound surface. Burns 1980;6:156.

26. Zawacki BE, Walker HL. An evaluation of patent blue V, brophenol blue, and tetracycline for the diagnosis of burn depth. Plast Reconstr Surg 1970;54:459.

27. Zuckerman A. Fluorescein fluorescence photography for the evaluation of burns. J Biol Photogr 1983;51:33.

28. Gatti J, La Rossa D, Silven-nan D, Hantfort C. Evaluation of the burn wound with perfusion flowmetry. J Trauma 1983;23:202.

29. Black KS, Hewitt CW, Miller DM. Burn depth evaluation with fluorometry: Is it really definitive? J Burn Care Rehabil 1986;7:313.

30. Celikoz B, Deveci M, Nisanci A. Early tangential excision with the guidance of methylene blue application. Annals Burns Fire Disasters 1999;XII(4).

31. Hauben DJ, Mahler D. Histological investigation of burn eschar and underlying recipient area in tangential early excision of burns. Burns 1979;5:160.

32. Kahn AM, McCrady VL, Rosen VJ. Burn wound biopsy. Scand J Plast Reconstr Surg 1979;13:53.

33. Ha RY, Nojiama K, Adam WP, Brown SA. Analysis of facial skin thickness: Defining the relative thickness index. Plast Reconstr Surg 2005;115:1769-73.

34. Southwood WF. The thickness of the skin. Plast Reconstr Surg 1955;15:423-9.

35. Benmeir PSA, Greber B, Vardy D, et al. An analysis of mortality in patients with burns covering 40 percent BSA or more: A retrospective review covering 24 years (1964-88). Burns 1991;17:402-5.

36. Mahler DBP, Ben Yakar Y, Greber B, et al. Treatment of the burned hand: Early surgical treatment (1975-85) vs conservative treatment (1964-74). A comparative study. Burns Incl Therm Inj 1987; $13: 45-8$

37. Rosenberg L, Weiss J, Shafir R. Algorithm for hand burns. Annals MBC 1990;2:191. 